\title{
A CONVERGÊNCIA CONTÁBIL AOS PADRÕES INTERNACIONAIS: Diferenças entre IFRS PMEs e CPC PME
}

\author{
Eder Eugenio Munhão ${ }^{1}$ \\ Ariel Lopes Torres ${ }^{2}$ \\ Adervaldo Chaves Ribeiro ${ }^{3}$ \\ Alex Sabino dos Santos ${ }^{4}$
}

\section{RESUMO}

O International Accounting Standards Board - IASB emitiu um conjunto de normas contábeis denominado International Financial Reporting Standards - IFRS e em atenção a essas demanda e necessidade de harmonização as normas internacionais o Brasil, a criação do Comitê de Pronunciamentos Contábeis se deu em 2005 pelo Conselho Federal de Contabilidade, por meio da Resolução CFC n ${ }^{\circ} 1.055$, de 07/10/2005, com a finalidade de elaborar os pronunciamentos contábeis brasileiros em conformidade as normas internacionais. A evolução em qualquer área técnica ou cientifica depende de diversos fatores, sendo que o fator econômico fica evidenciado em qualquer circunstância. $\mathrm{O}$ chamamento internacional a uma convergência mundial das normas contábeis já era esperado e o que faltava eram os ajustes e adequações necessárias ao alinhamento dos procedimentos. O objetivo deste estudo e investigar as diferenças entre as IFRS PMEs e os CPC PME, buscando identificar as dificuldades da legislação quanto à harmonização às normas internacionais. Para isso, foi realizado um estudo descritivo, utilizando-se as técnicas de coleta material da revisão bibliográfica e da pesquisa documental. Em seus resultados pode-se observar que a adequação da legislação principalmente pela Lei 11.638/07, possibilitou uma convergência aos padrões internacionais. As diferenças existentes entre as IFRS PMEs e os CPC PME, não inviabilizaram a convergência tendo em vista que as diferenças estruturais são por conta de adaptações a legislação vigente, as diferenças não são conceituais e estão dentro das necessidades e orientações das normas internacionais.

Palavras-chave: IFRS PMEs; CPC PME e Convergência aos padrões contábeis.

\section{INTRODUÇÃO}

A importância da convergência e clara, indiscutível e o elevado número de publicações sobre o tema demonstram essa importância, a convergência as normas internacionais facilita o investimento estrangeiro, e trouxe alterações significativas nas demonstrações contábeis. Criou-se o grupo ativo intangível, a extinta conta reserva de reavaliação foi substituída pela contas ajuste de avaliação e a utilização do Método da Equivalência Patrimonial para a avaliação dos investimentos.

\footnotetext{
${ }^{1}$ Mestrando em Ciências Contábeis do Minter UNISINOS/UNEMAT, e-mail: edermunhao@unemat.br ${ }^{2}$ Mestre em Administracion Y Finanzas pela Universidade de Extremadura (2003), Professor do curso de Ciências Contábeis da UNEMAT - Campus de Tangará da Serra, e-mail: ariel@unemat.br ${ }^{3}$ Mestre em Gestão de Empresa, Professor do curso de Ciências Contábeis da UNEMAT - Campus de Tangará da Serra, e-mail: adervaldoribeiro@gmail.br

${ }^{4}$ Acadêmico do Curso de Ciências Contábeis da UNEMAT - Campus de Tangará da serra, email: lextv2000@gmail.com 
A convergência contábil aos padrões internacionais: diferenças entre IFRS PMES e CPC PME

Eder Eugenio Munhão, Ariel Lopes Torres, Adervaldo Chaves Ribeiro, Alex Sabino dos Santos

Lopes, Galdi e Lima (2009) e Niyama e Silva (2008) ressaltam que os padrões editados pelo IASB baseiam-se em princípios, com princípios gerais de orientação e não regras detalhadas, possibilitando que a essência econômica se evidencie. Ainda que o IASB elaborou as IFRS com flexibilidade na das normas e que em alguns casos, que a adoção de mais de um procedimento contábil válido para uma mesma modalidade operacional.

Para Calixto (2010), há divergências de opiniões sobre o reflexo da adoção das IFRS em diversos países, pois não é possível a aceitação geral quando um novo padrão de normas e diretrizes é imposto, o que normalmente gera custos e dificuldades de adaptação e de interpretação. Nesse sentido, dentre os principais estudos que abordam essa temática, destaca-se a seguir os mais assemelhados com esta investigação.

Esses fatos remetem ao questionamente de que existem diferenças básicas e estruturais entre as IFRS para PMEs com os CPCs PMEs, observando-se possíveis adaptações em cumprimento a legislação no Brasil. Nesse sentido, o objetivo do trabalho é apresentar se há pontos de inferência entre as IFRS para PMEs e os CPCs PMEs. A relevância deste estudo pode ser justificada pela necessidade de uma maior discussão acadêmica e conceitual de temas relacionados ao processo de convergência dos padrões contábeis. A carência de bibliografias e trabalhos empíricos no Brasil limita o desenvolvimento de técnicas e práticas de aperfeiçoamento da contabilidade, tendo em vista estarmos ainda na aplicação da convergência às normas internacionais.

De acordo com Madeira, Silva e Almeida (2004) o processo de harmonização contábil com a finalidade de realizar mudanças nos sistemas e normas contábeis, tornando compatível as demonstrações contábeis, respeitando as peculiaridades e característica de cada pais. Ainda segundo os autores o fluxo de recursos econômicos e de profissionais entre empresas e mercados internacionais, são importantes vantagens da Harmonização Contábil.

\section{REFERENCIAL TEÓRICO}

\subsection{NORMAS INTERNACIONAIS DE CONTABILIDADE}

A evolução em qualquer área técnica ou cientifica depende de diversos fatores, sendo que o fator econômico fica evidenciado em qualquer circunstância. $O$ chamamento internacional a uma convergência mundial das normas contábeis já era esperado e o que faltava eram os ajustes e adequações necessárias ao alinhamento dos procedimentos. 
A convergência contábil aos padrões internacionais: diferenças entre IFRS PMES e CPC PME

Eder Eugenio Munhão, Ariel Lopes Torres, Adervaldo Chaves Ribeiro, Alex Sabino dos Santos

Esse convergência dependeu de mudanças que se deram em vários momentos da história recente da contabilidade brasileira. O desenvolvimento econômico no pais é uma das causas que levou a contabilidade ao desenvolvimento que se vê no pais. (NIYAMA, 2007).

Em relação ao futuro da contabilidade Hendriksen e Van Breda (1999), escrevem que "a contabilidade desenvolveu-se em resposta a mudanças no ambiente, novas descobertas e progressos tecnológicos. Não há motivo para crer que a contabilidade não continue a evoluir em resposta as mudanças que estamos observando".

O desenvolvimento dependeu de eventos ocorridos em diversos países, e foi impulsionado pelos avanços tecnológicos. Já Iudícibus (2006) afirma que a teoria contábil desenvolve-se graças ao grau de desenvolvimento, comercial, social e institucional das sociedades.

Iudícibus e Lisboa (2007, p. 6) asseguram que as vantagens à adoção dessas normas são inegáveis e que há "dificuldades para se conseguir esse suposto ideal”.

Iudícibus et al (2010, p xxvii), diz que a "linguagem contábil é universal, [...] e que tornou-se por demais importante para todos os países, não podendo ser mais praticada por cada um conforme seus próprios desejos".

De acordo com o Juarez Domingues Carneiro - Presidente do CFC (2010, p. 3):

Para o Brasil, a adoção das normas reflete em benefícios internos e externos. No campo externo, a adoção insere o País no contexto econômico mundial, ajudando a internacionalizar empresas e negócios. Internamente, com a criação do CPC, as normas regularizam e normatizam as características contábeis das empresas e faz a intermediação do debate entre representantes dos diversos segmentos do mercado brasileiro.

\subsection{CPC}

A criação do Comitê de Pronunciamentos Contábeis se deu em 2005 pelo Conselho Federal de Contabilidade, por meio da Resolução CFC n ${ }^{\circ}$ 1.055, de 07/10/2005, com a finalidade de elaborar os pronunciamentos contábeis brasileiros em conformidade as normas internacionais.

Segundo Costa, Yamamoto e Theóphilo (2011, p 2)

...baseado nas normas internacionais o Comitê produziu 63 documentos, sendo 42 pronunciamentos técnicos (denominados CPCs), 5 orientações técnicas (denominadas OCPCs), 15 interpretações técnicas (denominadas ICPCs) e a estrutura conceitual para a elaboração e apresentação das demonstrações contábeis (framework). 
A convergência contábil aos padrões internacionais: diferenças entre IFRS PMES e CPC PME

Eder Eugenio Munhão, Ariel Lopes Torres, Adervaldo Chaves Ribeiro, Alex Sabino dos Santos

\subsubsection{CPCs PMEs}

Homologado pela Resolução CFC $\mathrm{n}^{\circ} 1.255 / 09$, o CPC aprovou o Pronunciamento Técnico PME - Contabilidade para Pequenas e Médias Empresas, usando como base a IFRS para PMEs (IASB). Entrando em vigor no exercício 2010.

Em relação ao termo PME o CPC assim o definiu: as sociedades por ações fechadas (sem negociação de suas ações ou outros instrumentos patrimoniais ou de dívida no mercado e que não possuam ativos em condição fiduciária perante um amplo grupo de terceiros), mesmo que obrigadas à publicação de suas demonstrações financeiras.

\subsection{IFRS}

Para Meirelles Junior (2009, p. 7) as IFRS são:

O International Financial Reporting Standards, ou IFRS, são normas internacionais de relato financeiro, emitidas pelo IASB. O principal objetivo dessas normas é desenvolver um modelo único de normas contábeis internacionais de alta qualidade, que requeiram transparência e comparabilidade na elaboração de Demonstrações Contábeis, e que atendam ao público interessado nessas Demonstrações sejam eles investidores, administradores, analistas, pesquisadores ou quaisquer outros usuários e leitores de tais demonstrações.

\subsubsection{IFRS PMEs}

Conforme definição o IASB utiliza-se de normas para as entidades privadas sem obrigação de prestação publica de contas, essa definição encontra-se no Norma Internacional de Relatório Financeiro para Pequenas e Médias Empresas (IFRS para PMEs) (2009, p.12).

O IASB também desenvolve e publica uma norma separada destinada para aplicação a demonstrações financeiras para fins gerais de entidades e outros relatórios financeiros por entidades que em muitos países são referidas por uma série de termos, incluindo pequenas e médias empresas (PMEs), entidades privadas e entidades sem obrigação de prestação pública de contas. Esta norma é a Norma Internacional de Relatório Financeiro para Pequenas e Médias Empresas (IFRS para PMEs).

\subsection{VANTAGENS DA CONVERGENCIA}

Segundo Iudícibus e Lisboa (2007, p. 3), existe uma série de inegáveis vantagens na internacionalização:

(a) a qualidade média das normas é claramente superior às atualmente existentes;

(b) reduzem-se custos nas empresas (não terão que utilizar dois ou mais padrões ao mesmo tempo para efetuar os registros contábeis);

(c) facilita-se o entendimento e a comparação por parte de investidores internacionais;

(d) tem-se a impressão de que se entra no clube dos grandes.

\section{ASPECTOS METODOLÓGICOS}


A convergência contábil aos padrões internacionais: diferenças entre IFRS PMES e CPC PME

Eder Eugenio Munhão, Ariel Lopes Torres, Adervaldo Chaves Ribeiro, Alex Sabino dos Santos

\subsection{Método de pesquisa}

A metodologia foi a da pesquisa é descritiva e bibliográfica. Conforme descrito por Collis e Hussey (2005, pg. 25) "Descritiva: descreve o comportamento dos fenômenos. É usada para identificar e obter informações sobre as características de um determinado problema ou questão". Foi realizada uma pesquisa documental através da comparação das IFRS PMEs e os CPC PME, a técnica utilizada foi a de análise de conteúdo que é a busca da essência de um texto nos detalhes da informação seguindo-se as evidências disponíveis (MARTINS E THEÓFILO, 2009).

\section{DESCRIÇÃO E ANALISE DOS DADOS}

Para a análise dos dados, a fim de se alcançar o objetivo de identificar as diferenças entre as IFRS para PMEs e as CPC PME, optou-se pela utilização de revisão bibliográfica utilizando-se Norma Internacional de Relatório Financeiro para Pequenas e Médias Empresas (IFRS para PME's), PRONUNCIAMENTO TÉCNICO PME Contabilidade para Pequenas e Médias Empresas (Correlação às Normas Internacionais de Contabilidade - The International Financial Reporting Standard for Small and Medium-sized Entities (IFRS for SMEs)) e IFRS para PMEs ao seu alcance 2011 - Um guia para o amadurecimento dos conceitos do padrão contábil global.

\section{DESCRIÇÃO E ANALISE DOS DADOS}

Para a análise dos dados, a fim de se alcançar o objetivo de identificar as diferenças entre as IFRS para PMEs e as CPC PME, optou-se pela revisão bibliográfica utilizando-se das The International Financial Reporting Standard for Small and Medium-sized Entities - IFRS para PMEs e o CPC PME's.

Quadro 1: Diferenças entre as IFRS para PMEs e as CPC PME

\begin{tabular}{|l|}
\hline Conceitos e princípios gerais - São similares \\
\hline Apresentação das demonstrações financeiras - Apresentação da demonstração do resultado em separado \\
e combinação da demonstração do resultado abrangente com a demonstração das mutações do \\
patrimônio líquido. Fato este que é proibido na versão completa das IFRSs. \\
\hline Demonstração da posição financeira - São similares \\
\hline Demonstração do resultado e demonstração do resultado abrangente - Apresentação da demonstração \\
do resultado em separado e combinação da demonstração do resultado abrangente com a demonstração \\
das mutações do patrimônio líquido. Fato este que é proibido na versão completa das IFRSs. - Com \\
relação à versão completa dos CPCs, o resultado abrangente também poderá apresentar diferenças, tais \\
como as mudanças no valor justo de ativos financeiros disponíveis para venda; entretanto, os ganhos \\
sobre a reavaliação do imobilizado e do ativo intangível não serão diferenças com relação à versão \\
completa dos CPCs, uma vez que a Lei no $11.639 / 07$ eliminou a opção de reavaliação de ativos. - \\
\hline
\end{tabular}


Diferentemente da versão completa das IFRSs, a versão completa dos CPCs e CPC PMEs requerem que a contrapartida relativa à isenção da adoção inicial das IFRSs com relação ao custo atribuído seja registrada na rubrica "Ajuste de avaliação patrimonial”.

Demonstração das mutações do patrimônio líquido e demonstração dos lucros e prejuízos acumulados Em virtude das exigências legais brasileiras, diferentemente da versão completa das IFRSs, foi preciso ficar com uma das duas alternativas da norma no que diz respeito à demonstração do resultado, ou seja, apenas a apresentação da demonstração do resultado em separado à do resultado abrangente total. - Por outro lado, considerando que no Brasil é utilizada a demonstração das mutações do patrimônio líquido, foi incluída a alternativa de apresentar a demonstração do resultado abrangente como parte dessa demonstração ou, ainda, apresentá-la separadamente, ou seja, a versão completa do CPC (CPC 26 (R)) e do CPC PME permitem a combinação da demonstração do resultado abrangente com a demonstração das mutações do patrimônio líquido, fato este que é proibido na versão completa das IFRSs.

Demonstração dos fluxos de caixa - O CPC PME incentiva a apresentação da conciliação entre o resultado líquido e o fluxo de caixa das atividades operacionais quando o método direto é utilizado.

Notas explicativas às demonstrações financeiras - São similares

Demonstrações financeiras e consolidadas e separadas - O CPC PME possui referência para as técnicas de consolidação que constam no ICPC 09 - Demonstrações Contábeis Individuais, Demonstrações Separadas, Demonstrações Consolidadas e Aplicação do Método de Equivalência Patrimonial, na qual é utilizado o método de equivalência patrimonial para registro em demonstrações contábeis individuais dos investimentos em associadas, joint ventures e subsidiárias. - O ICPC 09 tem como objetivo determinar procedimentos específicos para a elaboração de demonstrações contábeis individuais enquanto estiver vigente a determinação legal da preparação das referidas demonstrações individuais.

Políticas contábeis, mudança de estimativas e correção de erros - São similares.

Instrumentos financeiros básicos - São similares

Outros tópicos sobre instrumentos financeiros - São similares

Estoques - São similares.

Investimentos em coligadas - • O CPC PME prevê que os investimentos em coligadas, controladas e controladas em conjunto somente podem estar avaliados pelo método de equivalência patrimonial, enquanto a IFRS para PMEs aceitam em certas situações o método de custo e valor justo.

Investimentos em empreendimentos controlados em conjunto (joint ventures) - O CPC PME apresenta as mesmas diferenças em relação à IFRS para PMEs. - Na versão completa dos CPCs somente a opção de contabilização usando a consolidação proporcional é permitida.

Propriedade para investimento - São similares.

Ativo imobilizado - Em virtude das exigências legais brasileiras, diferentemente da IFRS para PMEs, a reavaliação de ativo imobilizado somente poderá ser aplicada quando for permitida legalmente. - Na versão completa das IFRSs também não é permitida a escolha da política contábil baseada no modelo de reavaliação.

Ativos intangíveis, exceto ágio - São similares, exceto pelo fato de que o CPC não permite a reavaliação de intangíveis.

Combinações de negócios e ágio - O CPC PME apesar de sua similaridade na versão da IFRS para PMEs, ou seja, ambos levam em consideração a versão antiga da IFRS 3 (2004). As empresas brasileiras que pretendem ou são requeridas a adotarem a versão completa dos CPCs irão encontrar a versão da IFRS 3 (2008) traduzida através do CPC 15 Combinação de negócios, ou seja, a versão completa do CPC apresenta diferenças similares ao CPC PME a aquelas comentadas no tópico "Principais diferenças na versão completa das IFRSs". - O CPC PME possui referência para as técnicas de consolidação que constam no ICPC 09 - Demonstrações Contábeis Individuais, Demonstrações Separadas, Demonstrações Consolidadas e Aplicação do Método de Equivalência Patrimonial. O objetivo é demonstrar o tratamento contábil do ágio nas demonstrações contábeis individuais da entidade.

Arrendamentos - São similares.

Provisões, passivos contingentes e ativos contingentes - São similares.

Passivo e patrimônio líquido - São similares.

Receita - São similares.

Volume 2, Número 4

Jul./dez. 2013

Revista UNEMAT de Contabilidade

UNEMAT 
A convergência contábil aos padrões internacionais: diferenças entre IFRS PMES e CPC PME

Eder Eugenio Munhão, Ariel Lopes Torres, Adervaldo Chaves Ribeiro, Alex Sabino dos Santos

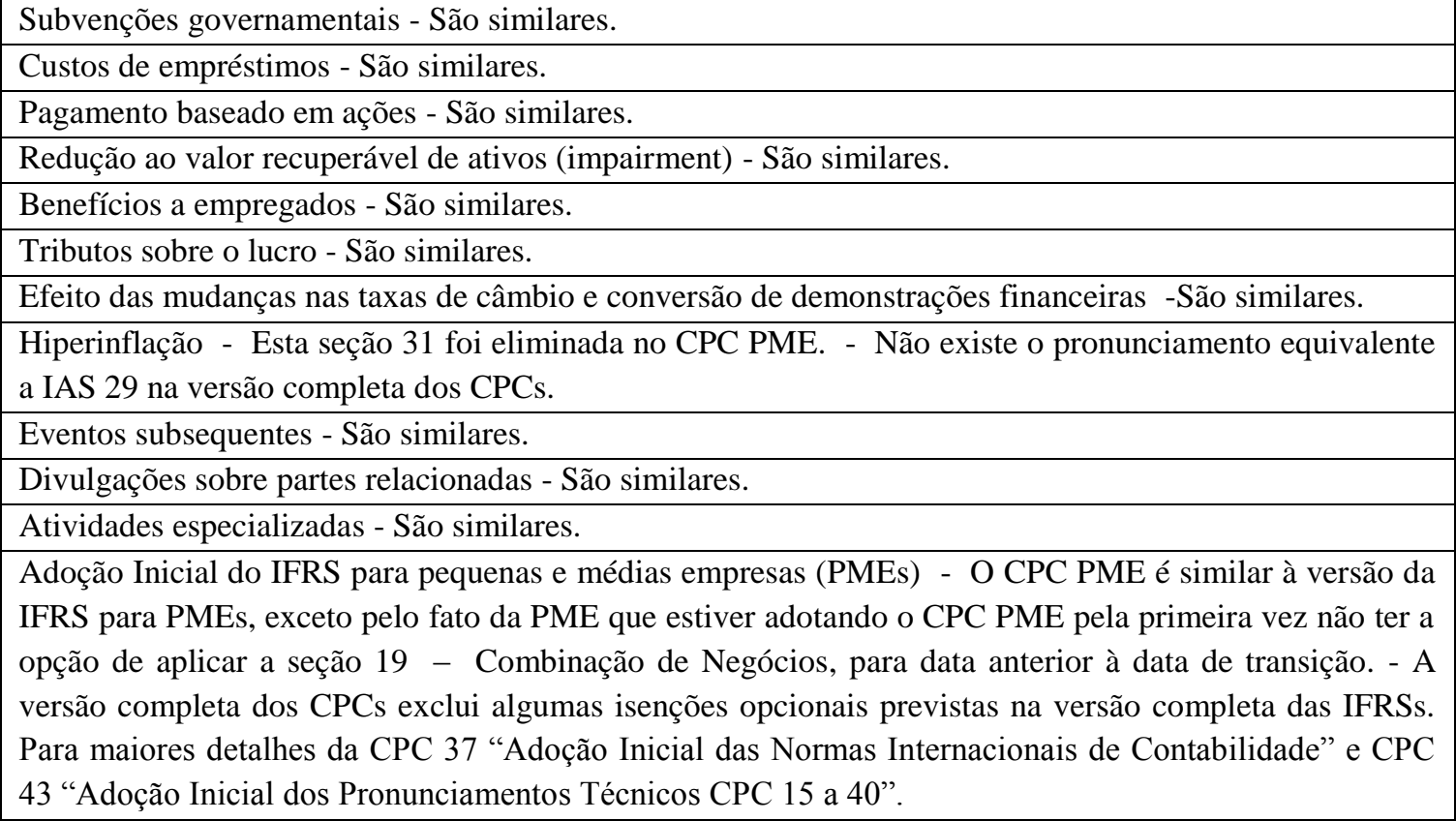

Fonte: Dados da Pesquisa.

\section{CONCLUSÃO}

A finalidade de uma harmonização das normas contábeis é indiscutível, quanto á verificação da qualidade das normas internacionais não é foco deste estudo. O Brasil a partir da Lei 11.638/07 estabeleceu um ponto de partida rumo á adequação de suas normas contábeis para a harmonização as normas internacionais.

Segundo Franco (2004) o ideal são normas uniformizadas em nível mundial, principalmente no caso da contabilidade, pois sua compreensão é uma necessidade tendo em vista que uma das funções da contabilidade e a da informação.

As diferenças existentes entre as IFRS PMEs e os CPC PME, não inviabilizaram a convergência tendo em vista que as diferenças estruturais são por conta de adaptações a legislação vigente, as diferenças não são conceituais e estão dentro das necessidades e orientações das normas internacionais.

\section{REFERÊNCIAS}

CALIXTO, Laura. Análise das pesquisas com foco nos impactos da adoção do IFRS em países europeus. Revista Contabilidade Vista \& Revista , Belo Horizonte, v. 21, n. 1, p. 157-187, jan./mar. 2010.

COSTA, Jorge Andrade, YAMAMOTO, Marina Mitiyo, THEÓPHILO, Carlos Renato, A aderência dos Pronunciamentos Contábeis do CPC às Normas Internacionais de Contabilidade. Congresso USP de Controladoria e Contabilidade, 11, 2011, São Paulo, Anais... Disponível em: 
A convergência contábil aos padrões internacionais: diferenças entre IFRS PMES e CPC PME

Eder Eugenio Munhão, Ariel Lopes Torres, Adervaldo Chaves Ribeiro, Alex Sabino dos Santos

$\langle$ http://www.congressousp.fipecafi.org/artigos112011/211.pdf $>$. Acesso em 6 jan. 2011.

DELOITTE. IFRS para PMEs ao seu alcance: um guia para sua jornada rumo ao padrão contábil global. Disponível em:

<http://www.deloitte.com.br/publicacoes/2007/Pocket_PME.pdf>. Acesso em: 18 out. 2011.

FRANCO, H. Harmonização Internacional das Normas Contábeis: um grande desafio para o profissional contábil. Anais... Congresso Brasileiro de Contabilidade, 17, 2004. HENDRIKSEN, Eldon S., VAN BREDA, Michael F., Teoria da Contabilidade.

Tradução de Antonio Zoratto Sanvicente. São Paulo: Atlas, 2007.

INTERNATIONAL ACCOUNTING STANDARDS BOARD (IASB). IFRS -

Normas internacionais de Relatório financeiro. São Paulo: Ibracon, 2009.

IUDÍCIBUS, Sérgio de, et al. Manual de Contabilidade Societária. São Paulo: Atlas, 2010.

IUDÍCIBUS, Sérgio de, LISBOA, Lázaro Plácido, Contabilidade: Entre Umas e Outras. Disponível em:

<http://www.ufpe.br/ricontabeis/index.php/contabeis/article/view/100/85>. Acesso em: 01 nov. 2011.

LOPES, Alexsandro Broedel; GALDI, Fernando Caio; LIMA, Iran Siqueira. Manual de Contabilidade e Tributação de instrumentos financeiros e derivativos. São Paulo: Atlas, 2009.

MADEIRA, Geová J. SILVA, Cátia B. A. ALMEIDA, Fabiana L. Harmonização de

Normas Contábeis: um estudo sobre as divergências entre normas contábeis internacionais e seus reflexos na contabilidade brasileira. Revista Mineira de Contabilidade. Belo Horizonte: Conselho Regional de Contabilidade de MG. Ano V, n. 16, 4. trim. 2004.

MARTINS, Gilberto de Andrade; THEÓPHILO, Carlos Renato. Metodologia da Investigação Científica para Ciências Sociais Aplicadas. 2. ed. São Paulo: Atlas, 2009.

MEIRELLES JUNIOR, Julio Candido de, Harmonização das normas internacionais de contabilidade.

< http://ww.aedb.br/seget/artigos09/58_HARMONIZACAO_DAS_NORMAS_INTERN ACIONAIS_DE_CONTABILIDADE.pdf> 2009 - Anais... VI SEGeT - Simpósio de Excelência em Gestão e Tecnologia - Acesso 06.10.2011

NIYAMA, Jorge Katsumi. Contabilidade Internacional. 1 ed. 4 reimpr. São Paulo: Atlas, 2007.

; SILVA, César Augusto Tibúrcio. Teoria da Contabilidade. São Paulo:

Atlas, 2008. 